\title{
THE TIMING OF PROTEIN SYNTHESIS REQUIRED FOR THE DEVELOPMENT OF THE SODIUM ACTION POTENTIAL IN EMBRYONIC SPINAL NEURONS ${ }^{1}$
}

\author{
LESLIE A. C. BLAIR \\ Department of Biology, B-022, University of California, San Diego, La Jolla, California 92093 \\ Reccived October 29, 1982; Revised January 21, 1983; Accepted February 11, 1983
}

\begin{abstract}
Embryonic amphibian neurons grown in dissociated cell culture extend neurites and can produce action potentials. The ionic dependence of the inward current of the action potential gradually changes from primarily calcium to primarily sodium. Early exposure of these neurons to protein synthesis inhibitors (cycloheximide, puromycin) blocked the appearance of neurites; later exposure blocked the normal change in the ionic basis of the action potential. These drugs apparently arrested the development of the sodium component of the action potential and, additionally, may have blocked a reduction in the calcium component. Inhibitor applied at still later times did not prevent the normal development of these traits. The development of voltage-sensitive delayed rectification was unaffected by the addition of inhibitor at any of the times tested.
\end{abstract}

The development of electrical excitability has been described for a population of embryonic spinal neurons, the Rohon-Beard cells, in the clawed frog Xenopus laevis (Baccaglini and Spitzer, 1977). In addition, cultured cells dissociated from the presumptive spinal portion of the neural plate of Xenopus embryos were found to become excitable and to change the ionic dependence of their action potentials along the same timetable as cells in vivo (Spitzer and Lamborghini, 1976; Willard, 1980). Apart from the opportunity to study processes which mimic those occurring in vivo, this culture system offers several advantages for the study of development. Cells are plated prior to the outgrowth of neurites and before the onset of impulse activity in Rohon-Beard cells (Baccaglini and Spitzer, 1977). The appearance of these traits in vitro therefore represents development, not regeneration. Furthermore, cultures are maintained in a defined medium devoid of exogenous hormones or growth factors. Thus, the development described in vitro may reflect intrinsic mechanisms, and the interpretation is not complicated by unknown contributions from added factors. Lastly, the cultures permit manipulations which could not be achieved in vivo.

To study the molecular mechanisms which control the choice to express a particular phenotype in development,

${ }^{1}$ I thank Dr. N. C. Spitzer for encouragement and advice. I also thank D. Berg, J. Bixby, W. Harris, J. Lamborghini, D. O’Dowd, and D. Zimmerman for helpful criticism. This work was supported by United States Public Health Service Training Grant GM 07313, National Institutes of Health Grant 15918, and Office of Naval Research Grant N00014-79-C-0748. it is necessary to describe the schedule of protein synthesis which contributes to the normal acquisition of that phenotype. In this paper, I describe the dependence of various differentiated neuronal phenotypes on protein synthesis, including the extension of neurites and the maturation of both inward and outward voltage-sensitive currents. Two inhibitors of protein synthesis, cycloheximide and puromycin, were used to determine the time periods during which the proteins required for the expression of these phenotypes are synthesized. A preliminary account of this work has appeared (Blair, 1981).

\section{Materials and Methods}

Cell cultures. Embryos of the frog Xenopus laevis were obtained as previously described (Gurdon, 1967) and were staged by the criteria of Nieuwkoop and Faber (1956). Dissociated cell cultures were prepared by procedures modified from those of Spitzer and Lamborghini (1976). At stage 15 (early neural fold formation), the neural plate and minimal amounts of underlying mesoderm were dissected out in sterile Steinberg's solution. The cells dissociated within $20 \mathrm{~min}$ after transfer to a divalent cation-free saline. Cells were then deposited on the bottom of $60-\mathrm{mm}$ Falcon tissue culture dishes in $4 \mathrm{ml}$ of plating medium. Cultures were incubated at $22^{\circ} \mathrm{C}$ and could be maintained throughout the experimental period without antibiotics. Cultures included a heterogeneous population of nerve and muscle as well as other cell types. Neurons were identified by the presence of neurites and growth cones. Neurite lengths and soma diameters were measured with an ocular micrometer.

Protein synthesis inhibilion. Cycloheximide and pur- 
omycin (Sigma Chemical Co.) were used to provide chronic inhibition of protein synthesis. The levels of inhibition were assayed biochemically, by measuring incorporation of $\left[{ }^{3} \mathrm{H}\right]$ leucine (Amersham, $50 \mathrm{Ci} / \mathrm{mmol}$ ) into the trichloroacetic acid-precipitable cell fraction. Specific incorporation was defined as the cpm per microgram of total protein (Lowry et al., 1951). Comparison of the specific incorporation into control and treated cultures established the percentage of inhibition. Additionally, inhibition was examined autoradiographically. Cultures were incubated for $8 \mathrm{hr}$ in $10 \mu \mathrm{Ci} / \mathrm{ml}$ of $\left[{ }^{3} \mathrm{H}\right]$ leucine and then were fixed in $2 \%$ glutaraldehyde, coated with Ilford nuclear emulsion, and exposed for 2 to 4 weeks. Cultures were developed and examined to determine the extent of labeling.

Electrophysiology. Intracellular recordings were made from cell bodies, visualized with phase contrast optics at $\times 500$, using glass micropipettes filled with $3 \mathrm{M}$ potassium acetate (90 to 140 megohms). An amplifier with a bridge circuit for current injection (W-P Instruments, model M4A) measured voltages, which were displayed on an oscilloscope or pen recorder.

Action potentials were elicited by injection of brief (1to 4-msec) pulses of depolarizing current. The cells were continuously perfused with saline. The ionic dependence of an action potential was determined using saline without sodium to eliminate inward sodium currents and saline containing $10 \mathrm{~mm} \mathrm{CoCl}$ to block voltage-dependent calcium currents (Hagiwara and Takahashi, 1967; Hagiwara et al., 1969). The duration of an action potential was measured from the maximum rate of rise to the maximum rate of fall of an impulse. Resting potentials of up to $-90 \mathrm{mV}$ were recorded, though lesser values were common. Only neurons with a recorded resting potential more negative than $-55 \mathrm{mV}$ were accepted. No significant difference in the shape or ionic dependence of the action potential was observed with resting potentials between -55 and $-90 \mathrm{mV}$.

Current-voltage relationships were studied by measuring the voltage response of the membrane to long (700to 800-msec) current pulses of small amplitude (typically -10 to $20 \mathrm{pA}$ ). These experiments were performed with a single electrode which was in balance to currents of $\pm 50 \mathrm{pA}$ before impaling the cell. Data were accepted only if the electrode response after withdrawal from the cell was less than $1 \mathrm{mV}$ to a current pulse of the largest magnitude used during the experiment. Voltage-dependent sodium and calcium currents were suppressed with tetrodotoxin (Calbiochem) and $\mathrm{CoCl}_{2}$, respectively. During these experiments the resting membrane potential was held constant at $-80 \mathrm{mV}$ by injection of $\mathrm{DC}$ current. This value was chosen because it was the most negative resting potential that was frequently recorded. Only neurons with a recorded resting potential more negative than $-65 \mathrm{mV}$ were used for these measurements; cells with less negative values proved unstable when hyperpolarized to $-80 \mathrm{mV}$. The input resistance $\left(R_{\text {in }}\right)$ was calculated as the slope of a line determined by linear regression analysis on a minimum of four points in the range of -80 to $-105 \mathrm{mV}$. The membrane potential at which delayed rectification was activated and the slope conductance at voltages just positive to this potential were determined as follows. A second line, in the region more depolarized than $-80 \mathrm{mV}$, was constructed by linear regression analysis on a minimum of four points. The initial point was chosen as that which deviated from the line determining the input resistance by more than any point in the range of -80 to $-105 \mathrm{mV}$. A least squares fit was made to this point and to points up to $15 \mathrm{pA}$ more positive. The points determining this experimentally derived resistance $\left(R^{*}\right)$ typically fell between -55 and $-70 \mathrm{mV}$. The intersection of this line $\left(R^{*}\right)$ and the line defining the input resistance $\left(R_{\text {in }}\right)$ was then calculated and taken as a measure of the point of onset of voltage-dependent delayed rectification. This procedure was employed because it provided a convenient measure of voltage sensitivity using the single-electrode voltage recording technique. The resistance measured in the region more depolarized than $-80 \mathrm{mV}$ is determined by the input resistance of the membrane and the resistance due to rectification. Accordingly, the resistance due to rectification was calculated by rearranging the terms for two resistances in parallel.

$$
R_{\text {rectified }}=\frac{\left(R_{\text {in }}\right) \cdot\left(R^{*}\right)}{\left(R_{\text {in }}\right)-\left(R^{*}\right)}
$$

The continuous voltage response of the membrane to a slow ramp of injected current was also examined. The membrane potential was set at $-100 \mathrm{mV}$ with hyperpolarizing DC current, and a 0- to 50-pA ramp of depolarizing current was injected over a 5-sec period.

Solutions. Embryos were dissected in Steinberg's solution containing (in $\mathrm{mM}$ ): $\mathrm{NaCl}, 58.2 ; \mathrm{KCl}, 0.7 ; \mathrm{Ca}\left(\mathrm{NO}_{3}\right)_{2}$, $0.4 ; \mathrm{MgSO}_{4}, 1.3$; Tris-base, $4.6(\mathrm{pH}$ adjusted to 7.8 with $1 \mathrm{~N} \mathrm{NaOH}$ ). Dissociating medium was Steinberg's solution free of $\mathrm{Ca}\left(\mathrm{NO}_{3}\right)_{2}$ and $\mathrm{MgSO}_{4}$, with $0.4 \mathrm{~mm}$ EDTA. Cells were plated and maintained in Steinberg's solution containing $9.6 \mathrm{mM} \mathrm{CaCl}_{2}$. Electrical recordings were performed in a saline of comparable osmolarity. Normal saline contained (in $\mathrm{mM}$ ): $\mathrm{NaCl}, 40 ; \mathrm{CaCl}_{2}, 10 ; \mathrm{KCl}, 3$; HEPES, 5 (pH 7.4). Sodium-free saline contained $40 \mathrm{~mm}$ Tris (base/ $\mathrm{HCl}$ ), substituted for $\mathrm{NaCl}$. Ten millimolar $\mathrm{CoCl}_{2}$ was added to normal saline without compensation for the change in osmolarity. Delayed rectification was studied in normal saline containing $1 \mu \mathrm{g} / \mathrm{ml}$ of tetrodotoxin and $10 \mathrm{mM} \mathrm{CoCl}_{2}$.

\section{Results}

Extent of inhibition of protein synthesis. When protein synthesis was measured in whole cultures by incorporation of $\left[{ }^{3} \mathrm{H}\right]$ leucine into acid-precipitable material, $0.6 \mu \mathrm{M}$ cycloheximide achieved $81 \%$ inhibition within $30 \mathrm{~min}$ and $89 \%$ within $2 \mathrm{hr}$. Puromycin at $100 \mu \mathrm{M}$ caused $94 \%$ blockage in $2 \mathrm{hr}$. Inhibition specifically associated with neurons was examined autoradiographically. With $0.6 \mu \mathrm{M}$ cycloheximide applied from $5 \mathrm{hr}$, neurons exhibited a level of autoradiographically assessed labeling which was substantially reduced below the level found in control neurons (Fig. 1, $C$ and $D$ ). The level of inhibition in neurons seems to be very similar to the $89 \%$ demonstrated for the cultures as a whole.

Both inhibitors caused a dose-dependent reduction in the number of cells differentiating morphologically and the premature death of those that differentiated; all cell types seemed to be affected. In most of the subsequent experiments $0.6 \mu \mathrm{M}$ cycloheximide was used because this concentration appeared to maximize the duration of cell 

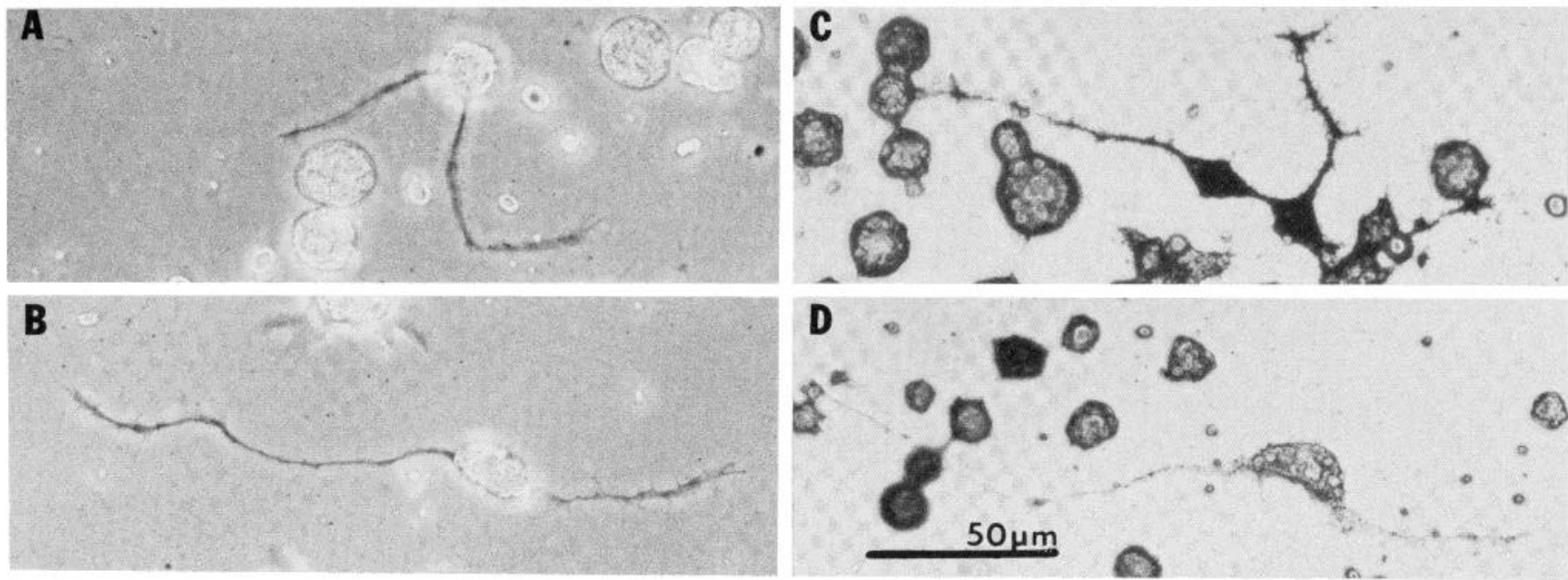

Figure 1. Neurons subjected to inhibitors of protein synthesis are morphologically similar to control neurons but do not incorporate $\left[{ }^{3} \mathrm{H}\right]$ leucine. $A$, A control neuron at $23 \mathrm{hr}$ in culture. $B$, A neuron from a sibling embryo, at $23 \mathrm{hr}$, that was chronically exposed to $0.6 \mu \mathrm{M}$ cycloheximide starting at $5 \mathrm{hr}$. Phase-dark processes extend from phase-bright cell bodies and terminate in growth cones. $C$, In brightfield illumination two control neurons, incubated in $\left[{ }^{3} \mathrm{H}\right]$ leucine, show dense radioactive labeling. $D$, A neuron, incubated in $\left[{ }^{3} \mathrm{H}\right]$ leucine and chronically exposed to $0.6 \mu \mathrm{M}$ cycloheximide from $5 \mathrm{hr}$, shows only light radioactive labeling above background. Neurons were examined at $20 \mathrm{hr}$ in culture $(C$ and $D)$. The extent of labeling of other, unidentified spherical cells and debris cannot be evaluated by the plane of focus shown in $C$ and $D$.

survival while maintaining a relatively high level of inhibition. In cultures that were chronically treated with $0.6 \mu \mathrm{M}$ cycloheximide from $5 \mathrm{hr}$, there was a rapid decrease, beginning at $24 \mathrm{hr}$, in the number of neurons. Accordingly, data were collected from neurons up to 24 $\mathrm{hr}$ in vitro. Cycloheximide at $10 \mu \mathrm{M}$ achieved $95 \%$ inhibition, but no cells survived longer than several hours. Puromycin $(100 \mu \mathrm{M})$ typically caused the death of most cells by approximately $20 \mathrm{hr}$ in culture, although the neurons that survived displayed a morphology similar to that of untreated neurons and electrophysiological properties indistinguishable from those of cycloheximidetreated neurons.

Effect of inhibition of protein synthesis on neurite outgrowth. Neurite outgrowth starts at 6 to $7 \mathrm{hr}$ after plating in untreated cultures. When chronic inhibition was initiated at $4 \mathrm{hr}$ in culture, no neurite extension was observed. If inhibition was started at $5 \mathrm{hr}$, neurites were extended and were not morphologically distinguishable from those of control neurons (Fig. $1, A$ and $B$ ). If inhibition was started slightly earlier, at $4.5 \mathrm{hr}$, neurites indistinguishable from control neurites were extended in approximately two-thirds of the cultures. When cultures were made from sibling embryos and examined from 6 to $24 \mathrm{hr}$ after plating, the average length and number of neurites, rate of neurite elongation, and cell body diameter were not significantly different in control and treated neurons (the Student's $t$ test; $N \geq 43$ neurons for each group). Table I shows the average length of neurites in control and inhibited neurons as a function of age. In other experiments, cycloheximide was applied within 2 $\mathrm{hr}$ of plating and subsequently was washed out after another 6 or $8 \mathrm{hr}$, presumably reversing the blockage of protein synthesis. Neurite extension was delayed by approximately 6 or $8 \mathrm{hr}$ and then appeared to proceed normally. This indicates that inhibition begun before 4.5 $\mathrm{hr}$ in culture did not cause the death of the presumptive neurons, but did prevent neurite outgrowth.
TABLE I

Extension of neurites in control neurons and neurons chronically inhibited from $5 \mathrm{hr}$ in culture ${ }^{a}$

\begin{tabular}{ccccc}
\hline \multirow{2}{*}{$\begin{array}{c}\text { Extension } \\
\text { of }\end{array}$} & \multicolumn{4}{c}{ Age in Culture (hr) } \\
\cline { 2 - 5 } Neurites & 6 & 12 & 18 & 24 \\
\hline Control & $29.15 \pm 2.70^{b}$ & $74.28 \pm 5.42$ & $123.18 \pm 8.96$ & $139.13 \pm 9.54$ \\
Treated & $33.53 \pm 3.18$ & $76.59 \pm 5.72$ & $118.13 \pm 9.62$ & $137.67 \pm 12.09$ \\
\hline
\end{tabular}

${ }^{a}$ Neurons were identified at $6 \mathrm{hr}$ in culture and measurements were made of the length of each neurite. The neurons were re-identified every $6 \mathrm{hr}$ up to 1 day in culture, and the lengths of the neurites were remeasured. Results are expressed as the mean neurite length \pm SEM; 46 control neurons and 43 treated neurons were examined. There was no statistical difference between the values for control and treated neurons at any age $(p>0.10)$

${ }^{b}$ All values are in microns.

Effect of inhibition on the development of the action potential. Control neurons impaled 6 to $9 \mathrm{hr}$ after plating exhibit action potentials of long duration, with a wide variability in impulse length from cell to cell (Figs. $2 A$ and 4). The depolarizing phase depends primarily on an influx of calcium ions, since a long-duration plateau persists when sodium is removed from the medium, as previously reported (Spitzer and Lamborghini, 1976; Willard, 1980). However, I found that although much of the response is lost when $10 \mathrm{~mm}$ cobalt is perfused over the cell, a slowly rising regenerative event remains (Fig. $2 A$ ). This component is approximately $10 \mathrm{msec}$ in duration and requires sodium ions: all response is lost when the neuron is bathed in saline that contains cobalt but is also sodium free. Thus, there is a minor sodium component in the inward current of the action potential at this age. The action potential of neurons inhibited at 4.5 to $5 \mathrm{hr}$ after plating and examined at 6 to $9 \mathrm{hr}$ is not significantly different from that found in controls (Fig. $2 B$ ).

As a function of age in culture, the action potential of untreated neurons decreases in duration and changes to 

Normal
$-\mathrm{Na}^{+}$
$+\mathrm{Co}^{++}$
Normal

A.
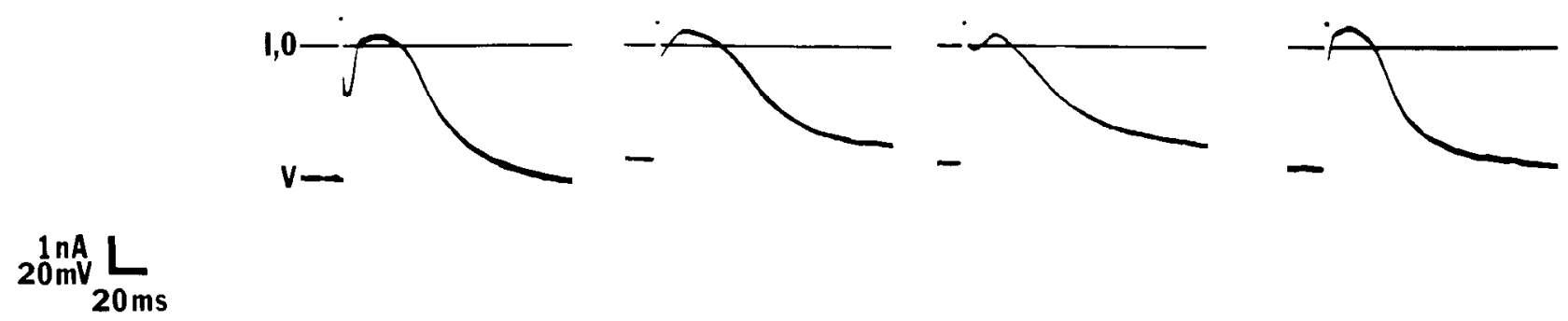

B.

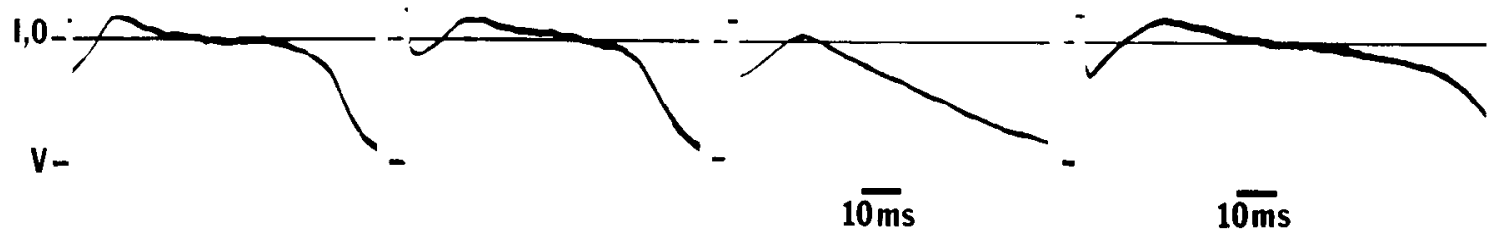

Figure 2. The ionic hasis of the neuronal action potential immediately following neurite outgrowth (6.5 hr in culture). Records are from one control and one protein synthesis-inhibited neuron. Depolarizing current pulses $(I)$ were adjusted to elicit action potentials $(V)$ which arose following termination of the pulse. The zero current level is the zero membrane potential $(0)$. Note the change in time scale for the final two traces in $B$. $A$, A control neuron produces a long-duration impulse which is not affected by removal of sodium $\left(-\mathrm{Na}^{+}\right)$from the medium. If cobalt is added to normal saline $\left(+\mathrm{Co}^{++}\right)$, a slowly rising and falling response remains, which can be blocked by removal of sodium (not shown). The original impulse reappears after return to normal saline. $N=11$. $B$, An experimental neuron treated with $0.6 \mu \mathrm{M}$ cycloheximide from $5 \mathrm{hr}$. The responses are similar to those of the control neuron. $N=13$.

a primarily sodium-dependent event (Spitzer and Lamborghini, 1976). After 1 day in culture, a regenerative response is absent or greatly reduced in saline that contains calcium but not sodium, indicating a decrease in the calcium-dependent component (Fig. $3 A$ ). The action potential duration has decreased more than 20 -fold by this time (Fig. 4). The component found at this stage in saline containing $\mathrm{CoCl}_{2}$ is tetrodotoxin sensitive (Spitzer and Lamborghini, 1976) and is carried by sodium ions. This sodium component is fast rising and of short duration $(1.47 \pm 0.16 \mathrm{msec}$, mean $\pm \mathrm{SEM} ; N=17)$ compared with the response seen in neurons at 6 to $9 \mathrm{hr}$ (cf. Figs. $2 A$ and $3 A$ ).

The action potentials of neurons subjected to protein synthesis inhibitors do not follow this developmental change. They remain primarily calcium dependent with a slowly rising sodium component (Fig. $3 B$ ). This is reflected in the length of action potentials in the treated neurons, which does not decrease with time in culture to the extent that it decreases in control neurons (Fig. 4). Except at the earliest times, the action potential in experimental neurons is significantly longer than in controls and it continues to exhibit the large variability seen in early controls. In addition, the sodium component in experimental neurons is slowly rising and long in duration $(9.88 \pm 1.52 \mathrm{msec} ; N=8)$ at 1 day in culture. It is indistinguishable from the early sodium component but is significantly longer $(p<0.001)$ than the later sodium component in control neurons. The resting potential does not change with age in culture and seems to be unaltered by the presence of inhibitor. Furthermore, the ionic dependence of the action potential is independent of the membrane potential in the tested range $(-55$ to -90 $\mathrm{mV}$ ). Therefore, the altered properties of the action potential in treated neurons cannot be accounted for by a change in resting potential.

Delayed rectification in control and protein synthesisinhibited neurons. The long duration of the action potential in older, inhibited neurons could occur in several ways. Inhibition prevents the normal development of the fast-rising inward sodium component. It may also block a loss of the inward calcium component. Additionally, the lack of a developmental increase in the outward rectifying current, presumably carried by potassium ions, could contribute to the greater duration of action potentials in treated neurons. The possibility that the development of the delayed rectifying current is retarded or arrested by inhibition was investigated by examining two properties of voltage-dependent delayed rectification in control and inhibited neurons as a function of age: the membrane potential at which delayed rectification is detectably activated and the change in membrane resistance which rectification causes. These were calculated as described under "Materials and Methods."

Figure 5 demonstrates the continuous change of membrane potential in response to a slow, continuous current ramp. Table II summarizes the results obtained with pulses of current. The results of these two methods were not detectably different. The rectifying resistance decreases with age (indicating a conductance increase) in both treated and untreated neurons; no significant difference between them is observed. The input resistances of 
A.

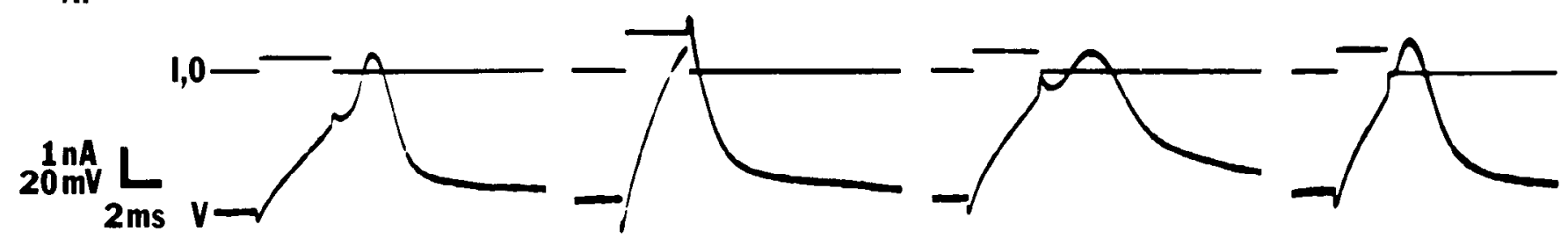

B.
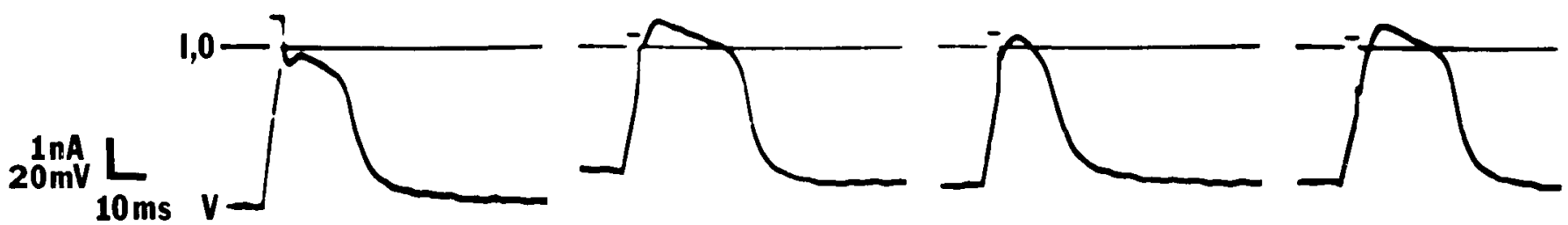

Figure 3. The ionic basis of the action potential in neurons at 1 day in culture. Records are from one control and one inhibited neuron. $A$, A control neuron produces a fast-rising regenerative response of short duration. This event is eliminated by removal of sodium; large current pulses cause only passive depolarization and repolarization of the membrane. Addition of cobalt to normal saline has little effect on the normal, short-duration action potential. $N=17$. All neurons produced a short-duration action potential; 4 of 17 were sodium dependent; 13 of 17 were dependent on both sodium and calcium. $B$, In an experimental neuron treated with cycloheximide from $5 \mathrm{hr}$, the response is long in duration and unaffected by removal of sodium. A slowly rising 10-msec sodium component persists in saline with cobalt. Note the time calibration in $B$ is 5 times that in $A$. $N=8$. Abbreviations are the same as in Figure 2.

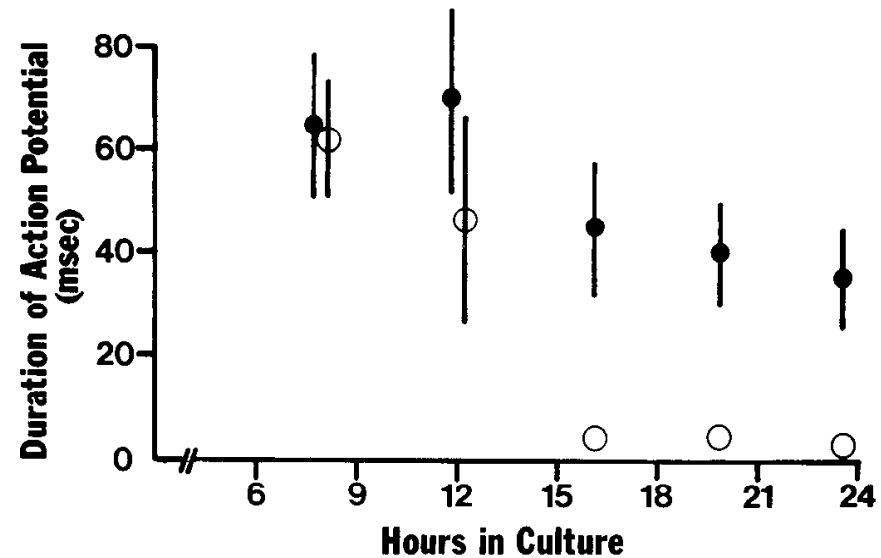

Figure 4. The duration of the action potential in control (O) and in experimental (O) neurons inhibited from $5 \mathrm{hr}$ in culture with $0.6 \mu \mathrm{M}$ cycloheximide or $100 \mu \mathrm{M}$ puromycin. Results are expressed as the mean $\pm \mathrm{SEM}, N \geq 20$ for all values. The error bars of the three oldest control groups are smaller than the circles denoting their means. From 6 to $13 \mathrm{hr}$ in culture the durations of the action potentials in control and treated neurons are not statistically different. In all later time periods durations in treated neurons are significantly longer than in controls ( $p$ $<0.001)$.

the control and inhibited neurons were the same. The voltage sensitivity of rectification, as assayed by the voltage at which rectification is detected, does not change with increasing age in culture and apparently is unaf-

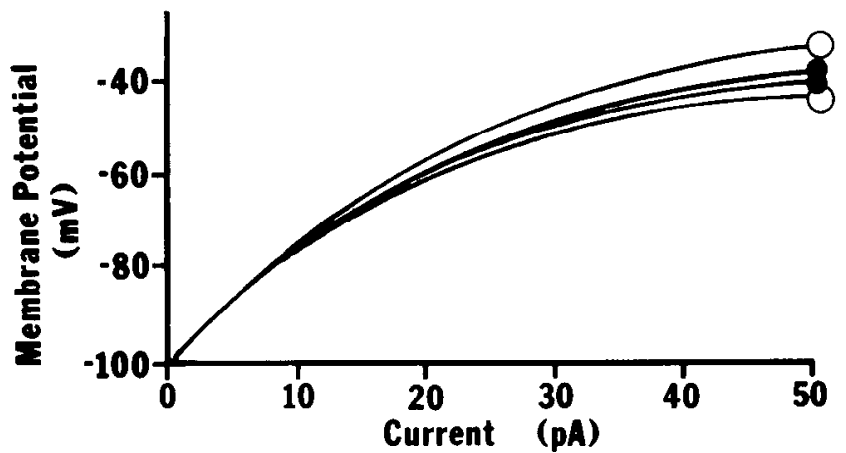

Figure 5. Current-voltage relationships of two control (O) and two experimental (O) neurons. Inward currents were suppressed with tetrodotoxin and $\mathrm{CoCl}_{2}$. Cells were held at -100 $\mathrm{mV}$, and a ramp of $10 \mathrm{pA} / \mathrm{sec}$ was injected over $5 \mathrm{sec}$; the rise in membrane potential was recorded as a function of the amount of injected current. The cells were 22 to $24 \mathrm{hr}$ old, and inhibition of experimental neurons was initiated $5 \mathrm{hr}$ after plating.

fected by the presence of inhibitor. Additionaily, there is no obvious difference between control and treated neurons in the time course of delayed rectification, since the duration of the delay between the beginning of the test pulse and the activation of rectifying currents appears unaltered by inhibition.

Effect of late addition of inhibitor on the action potential. The time of drug application affects the form of the action potential in treated neurons. If inhibition is 
started before $9 \mathrm{hr}$ in culture, the action potential is not detectably different from that found in treated neurons whose inhibition started at $5 \mathrm{hr}$. Inhibition initiated 13 hr after plating results in the neurons having primarily sodium-dependent action potentials of short duration (Fig. 6). In this case, the mean duration of action potentials in treated neurons at 22 to $24 \mathrm{hr}$ in culture $(3.15 \pm$ $0.80 \mathrm{msec}$ ) is not statistically different from that of controls $(2.42 \pm 0.46$ msec; $p>0.10$, the Student's $t$ test, $N$ $>20$ for each group). The variability, as measured by the standard error, is low (i.e., within 2-fold of control SEM). Application of inhibitor between 9 and $13 \mathrm{hr}$ gives intermediate values for both average duration and variability.

\section{Discussion}

A developmental change in the ionic dependence of the inward current of impulses has been observed in several cell types and seems to be a general feature in the development of electrical excitability (Spitzer, 1982). Previous studies have described this process in embry-

TABLE II

Development of delayed rectification in control and inhibited neurons $^{a}$

\begin{tabular}{lcc}
\hline Resistance and Rectification & \multicolumn{2}{c}{ Age in Culture (hr) } \\
\cline { 2 - 3 } & $8-11$ & $22-24$ \\
\hline Rectifying resistance (megohms) & & \\
$\quad$ Control & $3848 \pm 635$ & $1728 \pm 142$ \\
$\quad$ Treated & $\mathbf{4 4 0 8 \pm 6 3 0}$ & $\mathbf{1 6 8 3 \pm 1 0 9}$ \\
$\quad$ Onset of rectification (mV) & & \\
$\quad$ Control & & \\
$\quad$ Treated & $6.30 \pm 1.07$ & $9.13 \pm 1.23$ \\
\end{tabular}

"The membrane potential at which rectification is activated and the resistance of the cell above this potential were calculated as described under "Materials and Methods." The decrease in resistance due to rectification is termed here "rectifying resistance;" it describes a slope resistance between two membrane potentials, usually -55 to $-70 \mathrm{mV}$. Fxposure to $0.6 \mu \mathrm{M}$ cycloheximide hegan at $5 \mathrm{hr}$ after plating. Results are expressed as the mean $\pm \mathrm{SEM}, N=10$ for each value. The rectifying resistance of neurons at 8 to $11 \mathrm{hr}$ in culture is significantly larger than that found at 22 to $24 \mathrm{hr}$ in both control and inhibited neurons $(p<$ $0.005)$. Control values were not significantly different from experimental values at, either time $(p>0.25)$. There was no statistical difference in the voltage sensitivity of rectification between control and treated neurons $(p>0.25)$ or with increasing age $(p>0.10)$. The membrane potential was held at $-80 \mathrm{mV}$, and the values are expressed as millivolts depolarized from the holding potential. The input resistance was typically between 1000 and 4000 megohms in both treated and control neurons. No difference was observed between control and treated neurons in the time course of activation of delayed rectification. onic amphibian spinal neurons in vivo (Baccaglini and Spitzer, 1977) and in vitro (Spitzer and Lamborghini, 1976; Willard, 1980). I have examined the timing of protein synthesis necessary for the development of the sodium-dependent action potential, delayed rectification, and neurite outgrowth in cultured embryonic neurons. The results indicate that there are discrete times during which protein synthesis is required for the development of the fast-rising sodium spike and the regression of the calcium plateau.

These results suggest that the application of inhibitors at a particular stage of development has an effect specifically on protein synthesis and does not merely cause a general slowing of all metabolic processes. Neurite outgrowth and the development of delayed rectification are unaffected, while the development of the fast sodium spike is arrested. Protein synthesis, however, was incompletely inhibited by the concentrations of cycloheximide and puromycin used. The residual synthesis may account for the decrease in duration of the action potential seen in older treated neurons. An alternative explanation is that some synthesis of protein components necessary for a more mature action potential occurred prior to the onset of inhibition and became discernible only much later.

Previous work suggests that the protein synthetic events underlying the initial appearance of the action potential occur prior to neurite outgrowth, since cells that are extending neurites for the first time are electrically excitable. At early times in culture, neurons exhibit a calcium impulse both in the cell bodies (Spitzer and Lamborghini, 1976) and in the outgrowth neurites (Willard, 1980). In the experiments presented here, the earliest addition of inhibitor which does not block neurite outgrowth also permits the appearance of the calcium action potential.

The initial outgrowth of neurites seems to require protein synthesis at a specific time in development. Consistent with this hypothesis is the observation that the de novo extension of neurite-like processes in PC12 cells exposed to nerve growth factor is accompanied by an increase in protein synthesis (Garrels and Schubert, 1979; Gunning et al., 1981) and possibly also by a larger increase in synthesis of one or more specific proteins (McGuire and Greene, 1980). Murine superior cervical ganglia, however, will quickly regenerate neurites in explant culture, even in the presence of inhibitors of protein synthesis (Bloom and Black, 1979). Presumably, the rapid regeneration of neurites in this system relies on previously synthesized materials.

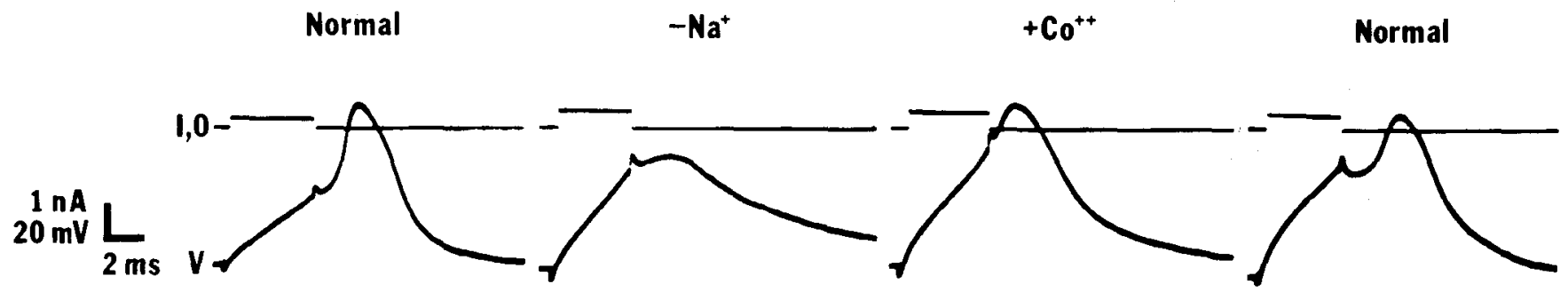

Figure 6. The ionic dependence of the action potential of a neuron subjected to inhibition of protein synthesis from 13 hr after plating, at age $24 \mathrm{hr}$. A short-duration regenerative response is elicited in normal saline; a small shoulder is observed in sodiumfree medium. The original fast-rising, short-duration impulse reappears when the medium is changed to include cobalt or when the neuron is returned to normal saline. $N=7$. Abbreviations are the same as in Figure 2 . 
In the present study, exposure of neurons to protein synthesis inhibitors as late as $9 \mathrm{hr}$ prevents the maturation of the sodium component of the action potential, which remains slowly rising and up to $20 \mathrm{msec}$ long. Additionally, a developmental loss of the calcium current may be blocked in these conditions. This possibility is hard to assess, since the actual decrement in the calcium conductance over the first day in culture in control neurons is unknown. The normal regression of the calcium plateau over this time could be explained by a more rapid activation of rectifying currents during the fastrising sodium spike or by an increase in rectifying currents not activated by voltage (e.g., a calcium-activated potassium current). If this explanation were correct, the maintenance of the calcium component in inhibited neurons could be a secondary effect of arresting the development of other currents. In contrast to the effect on inward current components, the normal development of the voltage-dependent outward currents seems to be unaffected. No tests were made for the presence of other outward currents.

When chronic inhibition is begun between 9 and $13 \mathrm{hr}$, the duration of the action potential is intermediate between that found in control neurons and that found in neurons inhibited from 4.5 to $5 \mathrm{hr}$. However, when inhibition is begun at $13 \mathrm{hr}$ or later, neurons develop action potentials not detectably different from those of the control neurons. This suggests that a minimum of the proteins neccssary for the later genesis of a mature sodium impulse are synthesized between 9 and $13 \mathrm{hr}$ in vitro. However, this interval may extend beyond $13 \mathrm{hr}$ for two reasons. The sodium component at 1 day in culture may not be a completely mature sodium spike; it is slightly longer than the sodium component found at 3 days. Synthesis of proteins beyond $13 \mathrm{hr}$ may be necessary for this small change. Additionally, the level of inhibition is high but not complete. If the residual protein synthesis is contributing to the appearance of the sodium spike in neurons inhibited at $13 \mathrm{hr}$, then $13 \mathrm{hr}$ will be earlier than the time of completion of protein synthesis.

O'Dowd $(1981,1983)$ has studied the effects of nearly complete inhibition of RNA synthesis on the development of embryonic amphibian neurons. When inhibition of RNA synthesis is initiated between 1.5 and $4 \mathrm{hr}$ in vitro, extension of neurites and the development of the calcium-dependent action potential proceed normally. In contrast, the normal maturation of the inward currents leading to a sodium-dependent impulse is prevented. Inhibition begun after $4 \mathrm{hr}$ in culture leads to partial development of the sodium action potential; blockage begun at approximately 12 to $15 \mathrm{hr}$ allows full maturation of the sodium spike.

The results of these two studies on protein and RNA synthesis suggest that the completion of translation of the proteins necessary for neurite outgrowth, the marker by which neurons are identified, follows completion of transcription of the necessary RNAs by about $3 \mathrm{hr}$.
Completion of transcriptional and translational events necessary for for the appearance of the calcium-dependent action potential could be separated by the same interval. In the case of the principally sodium-dependent action potential, the results suggest that the onset of translation follows the onset of transcription by a comparable period of time.

\section{References}

Baccaglini, P. I., and N. C. Spitzer (1977) Developmental changes in the inward current of the action potential of Rohon-Beard neurones. J. Physiol. (Lond.) 271: 93-117.

Blair, L. (1981) The timing of protein synthesis necessary for the acquisition of the $\mathrm{Na}^{+}$action potential during development. Soc. Neurosci. Abstr. 7: 245.

Bloom, E. M., and I. B. Black (1979) Metabolic requirements for differentiation of embryonic sympathetic ganglia cultured in the absence of exogenous nerve growth factor. Dev. Biol. 68: 568-578.

Garrels, J. I., and D. Schubert (1979) Modulation of protein synthesis by nerve growth factor. J. Biol. Chem. 254: 79787985.

Gunning, P. W., G. E. Landreth, P. Layer, M. Ignatius, and E. M. Shooter (1981) Nerve growth factor-induced differentiation of PC12 cells: Evaluation of changes in RNA and DNA metabolism. J. Neurosci. 1: 368-379.

Gurdon, J. B. (1967) African clawed frogs. In Methods in Developmental Biology, F. H. Wilt and N. K. Wessells, eds,, pp. 75-84, Crowell Press, New York.

Hagiwara, S., and K. Takahashi (1967) Surface density of calcium ions and calcium spikes in the barnacle muscle fiber membrane. J. Gen. Physiol. 50: 583-601.

Hagiwara, S., H. Hayashi, and K. Takahashi (1969) Calcium and potassium currents of the membrane of a barnacle muscle fibre in relation to the calcium spike. J. Physiol. (Lond.) 205: 115-129.

Lowry, O. H., N. J. Rosebrough, A. L. Farr, and R. J. Randall (1951) Protein measurement with the Folin phenol reagent. J. Biol. Chem. 193: 265-275.

McGuire, J. C., and L. A. Greene (1980) Stimulation by nerve growth factor of specific protein synthesis in rat $\mathrm{PC} 12$ pheochromocytoma cells. Neuroscience 5: 179-189.

Nieuwkoop, P. D., and J. Faber (1956) Normal Table of Xenopus laevis (Daudin), Elsevier-North Holland Publishing Co., Amsterdam.

O'Dowd, D. K. (1981) The timing of RNA synthesis necessary for the development of the $\mathrm{Na}^{+}$-dependent action potential in cultured neurons. Soc. Neurosci. Abstr. 7: 245.

O'Dowd, D. K. (1983) RNA synthesis dependence of action potential development in spinal cord neurons. Nature, in press.

Spitzer, N. C. (1982) The development of electrical excitability. In Dahlem Konferenzen 1982: Neuronal-Glial Cell Interrelationships, T. A. Sears, ed., pp. 77-91, Springer-Verlag, Berlin.

Spitzer, N. C., and J. E. Lamborghini (1976) The development of the action potential mechanism of amphibian neurons isolated in culture. Proc. Natl. Acad. Sci. U. S. A. 73: 16411645.

Willard, A. L. (1980) Electrical excitability of outgrowing neurites of embryonic neurones in cultures of dissociated neural plate of Xenopus laevis. J. Physiol. (Lond.) 301: 115-128. 